\title{
Self-Regulation of Breathing as a Primary Treatment for Anxiety
}

\author{
Ravinder Jerath $^{1}$ (D) Molly W. Crawford $^{1} \cdot$ Vernon A. Barnes $^{2} \cdot$ Kyler Harden $^{1}$
}

(C) Springer Science+Business Media New York 2015

\begin{abstract}
Understanding the autonomic nervous system and homeostatic changes associated with emotions remains a major challenge for neuroscientists and a fundamental prerequisite to treat anxiety, stress, and emotional disorders. Based on recent publications, the inter-relationship between respiration and emotions and the influence of respiration on autonomic changes, and subsequent widespread membrane potential changes resulting from changes in homeostasis are discussed. We hypothesize that reversing homeostatic alterations with meditation and breathing techniques rather than targeting neurotransmitters with medication may be a superior method to address the whole body changes that occur in stress, anxiety, and depression. Detrimental effects of stress, negative emotions, and sympathetic dominance of the autonomic nervous system have been shown to be counteracted by different forms of meditation, relaxation, and breathing techniques. We propose that these breathing techniques could be used as firstline and supplemental treatments for stress, anxiety, depression, and some emotional disorders.
\end{abstract}

Keywords Autonomic nervous system · Stress · Anxiety · Slow deep breathing . Membrane potential

Ravinder Jerath

Rj605r@aol.com

1 Augusta Women's Center, 2100 Central Ave., Suite \#7, Augusta, GA 30904, USA

2 Georgia Prevention Institute, Georgia Regents University, Augusta, GA, USA

\section{Introduction}

Though the source of human emotions is the brain and specific structures within the brain such as the amygdala, the experience of emotions causes widespread responses throughout the entire body (Cacioppo et al. 2000). An abundance of research has uncovered physiological changes that accompany emotions. For example, the autonomic nervous system (ANS) and respiratory activity have been shown to be closely associated with the experience of emotions (Kreibig 2010). The validity of the use of specific patterns of autonomic activity as an indicator for specific emotions is disputed. There are certainly characteristics of sympathetic/parasympathetic activity and respiration that are correlated with certain emotional states such as anxiety or happiness (Kop et al. 2011). We propose that negative mood states such as stress, anxiety, and depression cause sympathetic activation that is due to widespread depolarization throughout the brain and body, and that slow, deep breathing and meditation lead to parasympathetic activation due to widespread inhibition and hyperpolarization. Changes in neuronal cell membrane potentials may underlie neurophysiologic mechanisms of emotion (Murik 2005) and we propose that these membrane potential changes occur throughout the body as well. Extending the investigation of physiological attributes of emotion to include homeostatic changes in membrane potential due to changes in respiration and autonomic activation may further our understanding of the physiological states of various emotions (Sequeira et al. 2009).

A considerable body of clinical research has been conducted on the physiological and psychological changes observed during different emotional states using functional MRI (Patin and Hurlemann 2011), ANS monitoring (Kim et al. 2004), and studying neurotransmitter receptor 
physiology (Wahlestedt et al. 1993). Research findings linking emotions and anxiety with autonomic, respiratory, and cardiac activity have helped clarify the relationship between emotions and the physiology, suggesting an underlying mechanism based on cellular membrane potential changes in response to physiological changes induced by different emotional states.

Relaxation treatments, such as meditation, target the mind and body as a whole (Jacobs 2001) in comparison to pharmaceutical therapies which focus solely on neurotransmitter systems in the brain (Meyer and Quenzer 2005) and do not address homeostatic alterations arising from prolonged changes associated with emotions. Instead they bypass the brain's processing systems and act directly on mechanisms that control emotion (Nesse and Berridge 1997). Too often pharmacological treatments, such as anxiolytic drugs, have limited long term efficacy (Youngstedt and Kripke 2007), are symptom based, and are associated with severe side effects including adverse reactions, dependency (Buffett-Jerrott and Stewart 2002), addiction (Buffett-Jerrott and Stewart 2002; Lader 1994), relapse, and resistance to treatment (Starcevic 2012). A better understanding of the processes underlying human emotions may provide support for the administration of relaxation techniques such as meditation as a treatment for stress-related and anxiety disorders, as well as other psychiatric illnesses involving mood (Manzoni et al. 2008).

\section{Possible Role of Membrane Potential in Cardiorespiratory Modulation of ANS and Emotions}

Cardiac vagal motoneurons are hyperpolarized and strongly inhibited during inspiration, depolarized during the first half of expiration, and again demonstrate variable inhibition during the second half of expiration. We propose that slower respiration rates, which correspond to increased levels of cardiorespiratory synchronization (Porta et al. 2000), lead to a shift towards parasympathetic dominance via widespread hyperpolarization and inhibition of amygdala and thalamic cells (Jerath et al. 2012). Cardiorespiratory synchronization is an interaction between the cardiovascular and respiratory systems in which cardiac and respiratory signals synchronize (Schafer et al. 1998). Decreased levels of cardiorespiratory synchronization occur during stress and are negatively correlated to sympathetic activity (Zhang et al. 2010), exhibiting increased heart rate and irregular breathing (Malliani 1999). However, during meditation, the mind and body shift to a parasympathetic dominant state and correlate with increased levels of cardiorespiratory synchronization (Cysarz and Bussing 2005; Lo and Chang 2013; Wu and Lo 2010). Cardiorespiratory synchronization occurs primarily in a ratio of $4: 1$ and 5:1 during meditation, with four or five heartbeats for every one breath (Wu and Lo 2010). High levels of cardiorespiratory synchronization observed during meditation may be involved in modulating autonomic nervous system and amygdala activity (Jerath et al. 2014) and may underlie the mechanism by which meditation affects emotion states.

It has been established that during respiration, inspiration inhibits sympathetic nervous system activity (CzyzykKrzeska and Trzebski 1990; Dempsey et al. 2002; Seals et al. 1990; St Croix et al. 1999). In fact, slow-deep breathing has been shown to cause near-complete sympathoinhibition (Seals et al. 1990). This sympathoinhibition varies inversely with lung volume, with high lung volumes leading to the most inhibition (St. Croix et al. 1999). Most of this sympathoinhibition also occurs in the second half of inspiration. For example, during slow-deep breathing, inhibition occurs from mid-inspiration to early-mid expiration (Seals et al. 1990). However, subjects who perform deep breathing from an elevated starting lung volume experience this sympathoinhibition earlier during inspiration. Findings suggest that depth of breathing, breathing pattern, and starting lung volume all influence degree of sympathoinhibition, with slower, deeper breathing causing the most sympathoinhibition (Seals et al. 1990). In addition, a study found that the extrathoracic trachea exhibited slow oscillating membrane potentials predominantly during the post-inspiratory phase (Kondo et al. 1993). In contrast, irregular breathing such as Cheynes-Stokes respiration which can involve shallow and/or deep, rapid breathing and periods of apnea, modulates the ANS leading to excitation of the sympathetic nervous system (Leung et al. 2006). These results are a prime example of respiration directly modulating the ANS by inhibiting the sympathetic nervous system as well as respiration affecting membrane potential.

During mindfulness meditation, neurons in the cerebral cortex are inhibited by gamma-aminobutyric acid receptor neurons, also known as GABAergic neurons (Guglietti et al. 2013). GABAergic neurons are inhibitory neurons that increase firing in the cardiorespiratory network during inspiration (Frank and Mendelowitz 2012). They are highly involved in the creation of respiratory rhythms and they communicate between respiratory and cardiac centers in the medulla (Frank and Mendelowitz 2012). GABAergic neurons also modulate excitatory transmissions in the amygdala (Wu et al. 2009). In fact, genetic deletion or blockade of GABA receptors in the amygdala increases anxiety behaviors while increased GABAergic transmission reduces excitatory transmissions in the amygdala (Wu et al. 2007). Another study found that GABA-mediated inhibitory postsynaptic potentials, i.e., hyperpolarizations, were reduced in the basolateral amygdala of stressed rats and that negative emotional responses are the result of reduced feedback 
inhibition of the amygdala (Isoardi et al. 2007). Patients with panic disorders have been found to have a $22 \%$ reduction in GABA levels in the occipital cortex, suggesting that decreased levels of GABA may be involved in panic disorder pathophysiology (Goddard et al. 2001). In contrast, oral administration of GABA increases alpha waves and decreases beta waves, suggesting that GABA induces relaxation and reduces anxiety (Abdou et al. 2006). After a single yoga asana session, which consists of postures, pranayama (a yogic breathing exercise), meditation, and chanting, subjects experienced a $27 \%$ increase in GABA levels (Streeter et al. 2007). However, GABAergic neuronal activity throughout the brain is complex and may also be involved in vagal inhibition. For example, injection of a GABA receptor antagonist into the nucleus ambiguous of the brainstem shows a dose-dependent decrease in heart rate and blood pressure. This effect does not occur in any other areas of the brainstem, suggesting that GABA inhibits vagal outflow from the nucleus ambiguous (DiMicco et al. 1979). Inspiratory-modulated GABAergic neurons may be responsible for the inhibition of parasympathetic cardioinhibitory neurons that result in respiratory sinus arrhythmia (Frank and Mendelowitz 2012). These findings suggest that inspiration may promote inhibitory activity in respiratory and cardiac centers in the brainstem and other areas of the brain, such as the amygdala and cortex.

During stress and anxiety states there is widespread excitatory activity throughout the body and brain that increases activity in the amygdala (Davis 1992) and hypothalamic-pituitary-adrenal axis (Herman and Cullinan 1997) causing release of excitatory neurotransmitters and hormones (Ranabir and Reetu 2011), increased heart rate (Vrijkotte et al. 2000), respiration rate (Gomez et al. 2004; Masaoka and Homma 2001), blood pressure (Kulkarni et al. 1998; Vrijkotte et al. 2000), skin conductance (Storm et al. 2002), and muscle tension (Wijsman et al. 2010). During the sympathetic fight or flight response, heart rate increases due to an increase in the cell membrane depolarization rate of the sinoatrial node (Wu et al. 2009). In addition, membrane depolarization is essential for contraction of skeletal muscle (Liu et al. 2009), suggesting that increased muscle tension during stress may be the result of widespread depolarization. During stress, the release of the excitatory neurotransmitter glutamate in the amygdala (Reznikov et al. 2007), and prefrontal cortex is mediated by depolarization (Musazzi et al. 2010). Stress and depression are also associated with increased amygdala activity and chronic stress leads to neuronal hyperactivity in the amygdala, suggesting that a reduction in this excitatory drive may be a potential treatment (Padival et al. 2013). We propose that this excitatory activity is the result of widespread depolarization which is inhibited by slow, deep breathing and some types of meditation. Studies have found decreased activity in the amygdala during mindfulness meditation (Desbordes et al. 2012) and during non-meditative states after mindfulness training (Desbordes et al. 2012). This decrease in amygdala response, after meditation training, has been found in patients with social anxiety disorder (Goldin and Gross 2010) as well as healthy patients (Desbordes et al. 2012; Taylor et al. 2011).

Studies on Transcendental Meditation ${ }^{\circledR}$ have shown reduced activity in the thalamus and hippocampus (Newberg et al. 2006). We propose that inhibition of these emotional processing areas of the brain, during meditation, is caused by a shift from sympathetic to parasympathetic dominance facilitated by slow, deeper breathing and cardiorespiratory synchronization (Jerath and Barnes 2009). A study by Zagon and Kemeny found that low-intensity stimulation of the vagus nerve caused long-lasting slow hyperpolarization of neurons in the cerebral cortex. The study proposed that if stimulation of the vagus nerve were to be repeated, before the last inhibition response ended then sustained inhibition may be maintained (Zagon and Kemeny 2000). Animal studies have shown cardiorespiratory coupling ceases after bilateral vagotomy, suggesting that cardiorespiratory synchronization is mediated by the vagus nerve, which imparts parasympathetic control (Campbell and Egginton 2007; Dick et al. 2009; Topchiy et al. 2011). In addition, schizophrenic patients exhibit decreased levels of cardiorespiratory synchronization, which indicates decreased vagal modulation and inhibition in the brainstem (Peupelmann et al. 2009). A study by Masaoka and Homma found a positive correlation between increases in respiration frequency and anxiety scores during anticipatory anxiety (Masaoka and Homma 2001). In another study, electroencephalogram (EEG) dipole tracing revealed that 350-400 ms after the onset of inspiration there was a wave of positive potentials in limbic areas of the brain. These positive waves are referred to as respiration-related anxiety potentials (RAPs). RAPs originated in the right temporal pole in low anxiety subjects and originated in the amygdala in more anxious subjects (Masaoka and Homma 2000). These RAPs, produced during inspiration, illustrate how emotional states can lead to membrane potential changes of cells. As the frequency of respiration increases, due to anxiety, this leads to positive waves that increase membrane potentials and depolarize limbic areas of the brain. These RAPs, produced during inspiration, illustrate how interconnected respiration and emotion states are and provide evidence of respiration's influence on emotion areas of the brain. We hypothesize that anxiety and other stress-related emotions promote sympathetic dominance and subsequent widespread depolarization of emotion areas in the brain.

Parasympathetic stimulation leads to hyperpolarization of frog taste cells (Sato et al. 2006), suggesting that hyperpolarization may occur during parasympathetic 
dominance, similar to that which occurs during slow deep breathing and may occur during positive emotions. Under sympathetic dominance, which occurs during emotional states such as fear and stress, we propose that there is a homeostatic response of widespread depolarization. In addition, slow deep breathing may lead to the widespread inhibition of neuronal firing that occurs throughout the brain during slow-wave sleep and may be responsible for the restorative function of sleep (Jerath et al. 2014).

In addition to the many inhibitory mechanisms discussed that occur via hyperpolarization, oxygen may also play an important role in these proposed widespread membrane potential changes. The basis for membrane potential changes lies in the transfer of ions across cell membranes, creating a gradient. We propose that oxygenation, may be an important factor in the widespread membrane potential changes that may occur during slow, deep breathing and meditation. Oxygen is vital for the electron transport chain during cellular respiration (Alberts et al. 2002). In fact, the mitochondrial electron transport chain has been found to be inhibited in hypoxic placentas (Colleoni et al. 2013) and oxygen and cytochrome $\mathrm{C}$ are limiting factors of mitochondrial respiration (Gnaiger and Kuznetsov 2002). Electron acceptors, such as oxygen, are responsible for the proton gradient and hyperpolarization that occur in the electron transport chain during mitochondrial cellular respiration (Alberts et al. 2002) suggesting that fluctuations in oxygen, even minor fluctuations that occur during inspiration and expiration, may affect the degree of mitochondrial hyperpolarization and subsequently affect the rate of cellular respiration (Jerath et al. 2015). Slow deep breathing, which has been shown to increase oxygenation (Bernardi et al. 1998; Bilo et al. 2012), may therefore lead to a slight but widespread increase in hyperpolarization of cellular membranes (Jerath et al. 2015). In addition, the existence of voltage dependent channels that transfer ions between the mitochondrial outer membrane and the cytosol (Fieni et al. 2010; Kmita and Stobienia 2006) suggests that mitochondrial membrane potential changes may affect the entire cell.

\section{Breathing and Meditation Techniques for Reducing Negative Emotions}

In view of the close association between respiration, ANS activity, and emotions presented, it is apparent that individuals possess the ability to alter emotional states using the voluntary control of breathing and mindset. One of the oldest and arguably, most efficient treatments of excessive stress is controlled breathing (Everly and Lating 2013). Various types of techniques that involve slow, deep breathing such as yoga, pranayama, and some forms of meditation, have been practiced throughout history to increase well-being (Ospina et al. 2007). However, the clinical use of such practices, especially in current Western culture, has yet to gain widespread acceptance, though popularity is increasing. Breathing and meditation techniques are readily available, and do not pose the risk of side effects. However, patients may respond faster or more effectively to medication than some types of meditation. Medications may have advantages over meditation, such as convenience; whereas meditation and breathing techniques may require cost, time, and special training in addition to considerable time required for practice. In stress and anxiety states, motivation for meditation practice may be low and negative thought processes might reduce compliance with regular meditation practice. We propose that the practice of mindfulness and compassion meditation and the practice of positive mood states may contribute to widespread hyperpolarization by inhibiting excitatory signaling. Research has shown positive outcomes when these exercises are used as treatment for anxiety or stress-related disorders. A study on patients with asthma found that breath retraining improved control of asthma symptoms, panic, and anxiety (Laurino et al. 2012). In addition, a study on major depression found that mindfulness meditation was as effective as medication. The double blind study, found relapse rates of $27 \%$ in the medication group, $28 \%$ in the meditation group, and $71 \%$ in the placebo group (Stubenrauch 2011).

Another two potential treatments of emotion-related disorders is the use of pranayama or Sudarshan Kriya yogic (SKY) breathing. Both techniques have shown reductions in stress, anxiety, and/or depression symptoms in several studies (Bhimani et al. 2011; Brown and Gerbarg 2005a; Marshall et al. 2013). SKY breathing is a technique involving breathing cycles ranging from slow, calming breathing to fast, stimulating breathing (Zope and Zope 2013). SKY breathing was shown to be helpful in the reduction of negative emotional states such as stress, depression, post-traumatic stress disorder (PTSD), anxiety, and insomnia following major disasters such as tsunamis (Descilo et al. 2010) and Hurricane Katrina (Gerbarg and Brown 2005). These benefits were also reported in other clinical studies (Agte and Chiplonkar 2008; Brown and Gerbarg 2005a; Janakiramaiah et al. 2000). The slow breathing cycles are suggested to stimulate the vagus nerve (Brown and Gerbarg 2005b) while the fast breathing cycles provide mild sympathetic stimulation similar to regular exercise that may boost stress tolerance (Brown and Gerbarg 2005a). The combined cycles of slow and fast breathing may aid in emotional processing by reducing excitation with slow breathing and emotional calming (Zope and Zope 2013).

Pranayama breathing yields similar positive outcomes. For instance, pranayama practice over a 2 month period led to significant stress reductions in medical students 
(Bhimani et al. 2011). Three months of pranayama practice also decreased anxiety and depression levels in 60-70 year olds (Gupta et al. 2010). Significant reductions in stress and anxiety levels were achieved with short term practice of pranayama which also led to improvements in test performance (Nemati 2013). A program incorporating pranayama, yoga, and relaxation training found that severity of depression was greatly reduced at one and 3 month follow-ups (Naveen et al. 2013). In a comparison of techniques having positive impacts on mood and energy (both physical and mental), pranayama produced a significantly greater positive impact on mood and energy than relaxation and visualization techniques (Wood 1993). A study examining stress management, found that deep breathing, relaxation, meditation, and guided imagery techniques resulted in reduced levels of anxiety, anger, neuroticism, hopelessness, salivary cortisol, and respiration levels (Iglesias et al. 2012). Deep breathing exercises have also been shown to reduce PTSD-like symptoms and normalized abnormal cortisol levels (Kim et al. 2013).

While the efficacy of various techniques for positively adjusting emotions is gaining increasing support, the specific mechanism through which these exercises achieve their results is poorly understood. However, evidence has allowed for better understanding of characteristics of the underlying physiology of controlled breathing and meditation. Deep breathing and meditation practice leads to an overall reduction in sympathetic tone and an increase in parasympathetic output which combats increased sympathetic activity during stress (Brown and Gerbarg 2005b; Jerath et al. 2006; Streeter et al. 2012). Indeed, evidence shows reductions in sympathetic signatures of autonomic markers during controlled breathing (Pal et al. 2004). For example, skin conductivity increases during sympathetic activity (Cowings et al. 1986; Isu et al. 1987) while skin resistance increases during meditation, which is indicative of decreased sympathetic activity (Delmonte 1984; Telles et al. 1995; Wallace 1970; Wallace et al. 1971). In addition, heart rate variability (HRV), an indicator of the state of the ANS (Sztajzel 2004), increases as respiratory rate decreases (Song and Lehrer 2003). The highest HRV occurs at four breaths per minute and decreases as respiratory rate increases. A similar inverse relationship is demonstrated between cardiorespiratory synchronization and respiratory rate, with the highest cardiorespiratory synchronization occurring at lower respiratory rates (Porta et al. 2000). The ANS can affect many tissue cells simultaneously via diffuse release of neurotransmitters. Gap junctions between cardiac and smooth muscle cells can affect an entire tissue by spreading electrical activity from a single discharge from an autonomic nerve, and by releasing neurotransmitters and hormones into the blood that are circulated throughout the body (McCorry 2007). A study on the relaxation response during meditation found that during stress the subjects in the meditation group had the same levels of plasma norepinephrine as the nonmeditators but the responsiveness of the sympathetic nervous system was reduced in the meditators (Hoffman et al. 1982). The study demonstrates how the ANS can modulate responsiveness to neurotransmitters, suggesting that the modulation of the ANS may be a more powerful treatment tool than the current trend of targeting individual neurotransmitters in the brain. Though a study found that norepinephrine levels were not lowered by Transcendental Meditation $^{\circledR}$ in subjects throughout the day, they were found to be lower for meditators in the morning when compared with controls (Infante et al. 2001). Another study, utilizing an Integrated Amrita Meditation Technique involving meditation, pranayama, and yoga, found that practicing these techniques was effective in reducing adrenaline levels (Vandana et al. 2011). The mechanism by which meditation blocks or inhibits response to norepinephrine is now understood in terms of decreased activation and/or reactivity of the sympathoadrenal system and the hypothalamic-pituitary-adrenal axis (Innes and Selfe 2014). Meditation has also been shown to increase dopamine tone (Kjaer et al. 2002) and levels of 5-hydroxyindole-3-acetic acid, a metabolite of serotonin (Bujatti and Riederer 1976). Examination of these many studies shows that slow deep breathing and relaxation techniques can modulate the ANS, leading to homeostatic changes throughout the body and brain and can affect levels of and responsiveness to neurotransmitters. These techniques are therefore excellent candidates for treating various stress disorders.

Development of better technology to measure membrane potential activity with regards to respiratory and autonomic modulation during various emotion and meditation states may help further our understanding of the physiological mechanism underlying breathing and meditation techniques. We believe the shift in sympathovagal balance induced by controlled respiration and/or meditation leads to inhibition of negative emotions and widespread hyperpolarization which contributes to the beneficial effects observed following practices such as pranayama or mindfulness. Current technology does not allow for accurate and ongoing membrane potential measurements to be taken during meditation. There are some methods that have had some success in examining membrane potential changes, such as intramuscular electrodes to study somatic cells and various dipole tracing methods using EEG to study neuronal cells. However, these technologies have limited capabilities. They may not be able to detect subtle membrane potential changes, have varying levels of accuracy, and are unable to measure phenomenon over long periods of time. 


\section{Conclusion}

Emotions and respiration are closely linked in a complex feedback loop. Understanding this interrelationship between respiration and emotions is essential to better understand how to treat anxiety, stress, depression, and emotional disorders. Many of the detrimental effects of negative emotional states and sympathetic dominance of the ANS have been shown to be counteracted by different forms of meditation, relaxation, and breathing techniques. Meditation and breathing techniques reduce stress, anxiety, depression, and other negative emotional states. The underlying mechanism by which these and other benefits occur is poorly understood. We propose that the ANS is modulated by breathing so that in sympathetic dominant states like stress and anxiety, slow-deep breathing techniques and meditation can shift sympathetic dominance to parasympathetic dominance. This slow, deep breathing and cardiorespiratory synchronization may lead to homeostatic increases in cellular membrane potentials and a generalized decrease in intrinsic excitability of pacemakers such as the heart and amygdala, causing physiologic inhibition of negative emotions. We propose that these breathing techniques could be used as first-line and supplemental treatments for stress, anxiety, depression, and some emotional disorders. These disorders are mainly treated with medications that affect neurotransmitters in the brain, rather than treatments that affect the entire body and brain. Widespread homeostatic changes occur during stress and anxiety so treatments that shift the ANS from sympathetic to parasympathetic states can be very effective. Throughout this article we have demonstrated that emotions can affect respiration and respiration can also influence emotions, yet this well-established relationship is not utilized in conventional treatments. Breathing and meditation techniques are simple, easy, and cost-effective yet they are not widely used as treatments.

Conflict of interest No funding was received for this article. There is no conflict of interest to report.

\section{References}

Abdou, A. M., Higashiguchi, S., Horie, K., Kim, M., Hatta, H., \& Yokogoshi, H. (2006). Relaxation and immunity enhancement effects of gamma-aminobutyric acid (GABA) administration in humans. BioFactors, 26(3), 201-208.

Agte, V. V., \& Chiplonkar, S. A. (2008). Sudarshan Kriya yoga for improving antioxidant status and reducing anxiety in adults. Alternative and Complementary Therapies, 14(2), 96-100. doi:10.1089/act.2008.14204.

Alberts, B., Amodio, J., Lewis J., Raff, M., K., Roberts, K., Walter, P. (2002). The mitochondrion. Molecular biology of the cell (4th edn). New York: Garland Science.
Bernardi, L., Spadacini, G., Bellwon, J., Hajric, R., Roskamm, H., \& Frey, A. W. (1998). Effect of breathing rate on oxygen saturation and exercise performance in chronic heart failure. Lancet, 351(9112), 1308-1311. doi:10.1016/s0140-6736(97)10341-5.

Bhimani, N. T., Kulkarni, N. B., Kowale, A., \& Salvi, S. (2011). Effect of Pranayama on stress and cardiovascular autonomic function. Indian Journal of Physiology and Pharmacology, 55(4), 370-377.

Bilo, G., Revera, M., Bussotti, M., Bonacina, D., Styczkiewicz, K., Caldara, G., et al. (2012). Effects of slow deep breathing at high altitude on oxygen saturation, pulmonary and systemic hemodynamics. PLoS One, 7(11), e49074. doi:10.1371/journal.pone. 0049074.

Brown, R. P., \& Gerbarg, P. L. (2005a). Sudarshan kriya yogic breathing in the treatment of stress, anxiety, and depression. Part II-Clinical applications and guidelines. Journal of Alternative and Complementary Medicine, 11(4), 711-717. doi:10.1089/ acm.2005.11.711.

Brown, R. P., \& Gerbarg, P. L. (2005b). Sudarshan Kriya yogic breathing in the treatment of stress, anxiety, and depression: Part I-Neurophysiologic model. Journal of Alternative and Complementary Medicine, 11(1), 189-201. doi:10.1089/acm.2005. 11.189.

Buffett-Jerrott, S. E., \& Stewart, S. H. (2002). Cognitive and sedative effects of benzodiazepine use. Current Pharmaceutical Design, $8(1), 45-58$.

Bujatti, M., \& Riederer, P. (1976). Serotonin, noradrenaline, dopamine metabolites in transcendental meditation-technique. Journal of Neural Transmission, 39(3), 257-267.

Cacioppo, J. T., Bernston, G. G., Larsen, J. T., Poehlmann, K. M., \& Ito, T. (2000). The psychophysiology of emotion (2nd ed.). New York: Guilford Press.

Campbell, H. A., \& Egginton, S. (2007). The vagus nerve mediates cardio-respiratory coupling that changes with metabolic demand in a temperate nototheniod fish. Journal of Experimental Biology, 210(Pt 14), 2472-2480. doi:10.1242/jeb.003822.

Colleoni, F., Padmanabhan, N., Yung, H. W., Watson, E. D., Cetin, I., Tissot van Patot, M. C., et al. (2013). Suppression of mitochondrial electron transport chain function in the hypoxic human placenta: A role for miRNA-210 and protein synthesis inhibition. PLoS One, 8(1), e55194. doi:10.1371/journal.pone.0055194.

Cowings, P. S., Suter, S., Toscano, W. B., Kamiya, J., \& Naifeh, K. (1986). General autonomic components of motion sickness. Psychophysiology, 23(5), 542-551.

Cysarz, D., \& Bussing, A. (2005). Cardiorespiratory synchronization during Zen meditation. European Journal of Applied Physiology, 95(1), 88-95. doi:10.1007/s00421-005-1379-3.

Czyzyk-Krzeska, M. F., \& Trzebski, A. (1990). Respiratory-related discharge pattern of sympathetic nerve activity in the spontaneously hypertensive rat. Journal of Physiology, 426, 355-368.

Davis, M. (1992). The role of the amygdala in fear and anxiety. Annual Review of Neuroscience, 15, 353-375. doi:10.1146/ annurev.ne.15.030192.002033.

Delmonte, M. M. (1984). Physiological responses during meditation and rest. Biofeedback and Self Regulation, 9(2), 181-200.

Dempsey, J. A., Sheel, A. W., St Croix, C. M., \& Morgan, B. J. (2002). Respiratory influences on sympathetic vasomotor outflow in humans. Respiratory Physiology and Neurobiology, 130(1), 3-20.

Desbordes, G., Negi, L. T., Pace, T. W. W., Wallace, B. A., Raison, C. L., \& Schwartz, E. L. (2012). Effects of mindful-attention and compassion meditation training on amygdala response to emotional stimuli in an ordinary, non-meditative state. Frontiers in Human Neuroscience. doi:10.3389/fnhum.2012.00292.

Descilo, T., Vedamurtachar, A., Gerbarg, P. L., Nagaraja, D., Gangadhar, B. N., Damodaran, B., et al. (2010). Effects of a 
yoga breath intervention alone and in combination with an exposure therapy for post-traumatic stress disorder and depression in survivors of the 2004 South-East Asia tsunami. Acta Psychiatrica Scandinavica, 121(4), 289-300. doi:10.1111/j. 1600-0447.2009.01466.x.

Dick, T. E., Baekey, D. M., Paton, J. F., Lindsey, B. G., \& Morris, K. F. (2009). Cardio-respiratory coupling depends on the pons. Respiratory Physiology and Neurobiology, 168(1-2), 76-85. doi:10.1016/j.resp.2009.07.009.

DiMicco, J. A., Gale, K., Hamilton, B., \& Gillis, R. A. (1979). GABA receptor control of parasympathetic outflow to heart: Characterization and brainstem localization. Science, 204(4397), $1106-1109$.

Everly, G., Jr., \& Lating, J. (2013). Voluntary control of respiration patterns. A clinical guide to the treatment of the human stress response (pp. 223-235). Springer: New York.

Fieni, F., Parkar, A., Misgeld, T., Kerschensteiner, M., Lichtman, J. W., Pasinelli, P., \& Trotti, D. (2010). Voltage-dependent inwardly rectifying potassium conductance in the outer membrane of neuronal mitochondria. Journal of Biological Chemistry, 285(35), 27411-27417. doi:10.1074/jbc.M110.131243.

Frank, J. G., \& Mendelowitz, D. (2012). Synaptic and intrinsic activation of GABAergic neurons in the cardiorespiratory brainstem network. PLoS One, 7(5), e36459. doi:10.1371/ journal.pone.0036459.

Gerbarg, P. L., \& Brown, R. P. (2005). Yoga: A breath of relief for Hurricane Katrina refugees. Current Psychiatry, 4, 55-67.

Gnaiger, E., \& Kuznetsov, A. V. (2002). Mitochondrial respiration at low levels of oxygen and cytochrome c. Biochemical Society Transactions, 30(2), 252-258.

Goddard, A. W., Mason, G. F., Almai, A., Rothman, D. L., Behar, K. L., Petroff, O. A., et al. (2001). Reductions in occipital cortex GABA levels in panic disorder detected with 1 h-magnetic resonance spectroscopy. Archives of General Psychiatry, 58(6), $556-561$.

Goldin, P. R., \& Gross, J. J. (2010). Effects of mindfulness-based stress reduction (MBSR) on emotion regulation in social anxiety disorder. Emotion, 10(1), 83-91. doi:10.1037/a0018441.

Gomez, P., Stahel, W. A., \& Danuser, B. (2004). Respiratory responses during affective picture viewing. Biological Psychology, 67(3), 359-373. doi:10.1016/j.biopsycho.2004.03.013.

Guglietti, C. L., Daskalakis, Z. J., Radhu, N., Fitzgerald, P. B., \& Ritvo, P. (2013). Meditation-related increases in GABAB modulated cortical inhibition. Brain Stimulation, 6(3), 397-402. doi:10.1016/j.brs.2012.08.005.

Gupta, P. K., Kumar, M., Kumari, R., \& Deo, J. (2010). Anulomaviloma pranayama and anxiety and depression among the aged. Journal of the Indian Academy of Applied Psychology, 36(1), $159-164$.

Herman, J. P., \& Cullinan, W. E. (1997). Neurocircuitry of stress: Central control of the hypothalamo-pituitary-adrenocortical axis. Trends in Neurosciences, 20(2), 78-84.

Hoffman, J. W., Benson, H., Arns, P. A., Stainbrook, G. L., Landsberg, G. L., Young, J. B., \& Gill, A. (1982). Reduced sympathetic nervous system responsivity associated with the relaxation response. Science, 215(4529), 190-192.

Iglesias, S. L., Azzara, S., Argibay, J. C., Arnaiz, M. L., de Valle Carpineta, M., Granchetti, H., \& Lagomarsino, E. (2012). Psychological and physiological response of students to different types of stress management programs. American Journal of Health Promotion, 26(6), e149-e158. doi:10.4278/ajhp.110516QUAL-199.

Infante, J. R., Torres-Avisbal, M., Pinel, P., Vallejo, J. A., Peran, F., Gonzalez, F., et al. (2001). Catecholamine levels in practitioners of the transcendental meditation technique. Physiology and Behavior, 72(1-2), 141-146.
Innes, K. E., \& Selfe, T. K. (2014). Meditation as a therapeutic intervention for adults at risk for Alzheimer's disease - potential benefits and underlying mechanisms. Frontiers in Psychiatry. doi:10.3389/fpsyt.2014.00040.

Isoardi, N. A., Bertotto, M. E., Martijena, I. D., Molina, V. A., \& Carrer, H. F. (2007). Lack of feedback inhibition on rat basolateral amygdala following stress or withdrawal from sedative-hypnotic drugs. European Journal of Neuroscience, 26(4), 1036-1044. doi:10.1111/j.1460-9568.2007.05714.x.

Isu, N., Koo, J., \& Takahashi, N. (1987). Changes of skin potential level and of skin resistance level corresponding to lasting motion discomfort. Aviation, Space and Environmental Medicine, 58(2), 136-142.

Jacobs, G. D. (2001). Clinical applications of the relaxation response and mind-body interventions. Journal of Alternative and Complementary Medicine, 7(Suppl 1), S93-101.

Janakiramaiah, N., Gangadhar, B. N., Naga Venkatesha Murthy, P. J., Harish, M. G., Subbakrishna, D. K., \& Vedamurthachar, A. (2000). Antidepressant efficacy of sudarshan kriya yoga (SKY) in melancholia: a randomized comparison with electroconvulsive therapy (ECT) and imipramine. Journal of Affective Disorders, 57(1-3), 255-259.

Jerath, R., \& Barnes, V. A. (2009). Augmentation of mind-body therapy and role of deep slow breathing. Journal of Complementary and Integrative Medicine. doi:10.2202/1553-3840. 1299.

Jerath, R., Barnes, V. A., \& Crawford, M. W. (2014). Mind-body response and neurophysiological changes during stress and meditation: central role of homeostasis. Journal of Biological Regulators and Homeostatic Agents, 28(4), 545-554.

Jerath, R., Barnes, V. A., Dillard-Wright, D., Jerath, S., \& Hamilton, B. (2012). Dynamic change of awareness during meditation techniques: Neural and physiological correlates. Frontiers $\mathrm{Hu}$ man Neuroscience, 6, 131. doi:10.3389/fnhum.2012.00131.

Jerath, R., Crawford, M. W., Barnes, V. A., \& Harden, K. (2015). Widespread depolarization during expiration: A source of respiratory drive? Medical Hypotheses, 84(1), 31-37. doi:10. 1016/j.mehy.2014.11.010.

Jerath, R., Edry, J. W., Barnes, V. A., \& Jerath, V. (2006). Physiology of long pranayamic breathing: Neural respiratory elements may provide a mechanism that explains how slow deep breathing shifts the autonomic nervous system. Medical Hypotheses, 67(3), 566-571. doi:10.1016/j.mehy.2006.02.042.

Jerath, R., Harden, K., Crawford, M., Barnes, V. A., \& Jensen, M. (2014). Role of cardiorespiratory synchronization and sleep physiology: Effects on membrane potential in the restorative functions of sleep. Sleep Medicine,. doi:10.1016/j.sleep.2013.10. 017.

Kim, K. H., Bang, S. W., \& Kim, S. R. (2004). Emotion recognition system using short-term monitoring of physiological signals. Medical Biological Engineering Computing, 42(3), 419-427.

Kim, S. H., Schneider, S. M., Bevans, M., Kravitz, L., Mermier, C., Qualls, C., \& Burge, M. R. (2013). PTSD symptom reduction with mindfulness-based stretching and deep breathing exercise: Randomized controlled clinical trial of efficacy. Journal of Clinical Endocrinology and Metabolism, 98(7), 2984-2992. doi:10.1210/jc.2012-3742.

Kjaer, T. W., Bertelsen, C., Piccini, P., Brooks, D., Alving, J., \& Lou, H. C. (2002). Increased dopamine tone during meditationinduced change of consciousness. Brain Research. Cognitive Brain Research, 13(2), 255-259.

Kmita, H., \& Stobienia, O. (2006). The VDAC channel as the mitochondria function regulator. Postepy Biochemii, 52(2), 129-136.

Kondo, T., Kobayashi, I., Hirokawa, Y., Ohta, Y., Yamabayashi, H., \& Arita, H. (1993). Centrally driven slow oscillating potential of 
extrathoracic trachea. Journal of Applied Physiology (1985), 74(3), 1066-1072.

Kop, W. J., Synowski, S. J., Newell, M. E., Schmidt, L. A., Waldstein, S. R., \& Fox, N. A. (2011). Autonomic nervous system reactivity to positive and negative mood induction: The role of acute psychological responses and frontal electrocortical activity. Biological Psychology, 86(3), 230-238. doi:10.1016/j. biopsycho.2010.12.003.

Kreibig, S. D. (2010). Autonomic nervous system activity in emotion: A review. Biological Psychology, 84(3), 394-421. doi:10.1016/j. biopsycho.2010.03.010.

Kulkarni, S., O’Farrell, I., Erasi, M., \& Kochar, M. S. (1998). Stress and hypertension. WMJ: Official Publication of the State, 97(11), 34-38.

Lader, M. (1994). Anxiolytic drugs: Dependence, addiction and abuse. European Neuropsychopharmacology, 4(2), 85-91.

Laurino, R. A., Barnabe, V., Saraiva-Romanholo, B. M., Stelmach, R., Cukier, A., \& Nunes Mdo, P. (2012). Respiratory rehabilitation: A physiotherapy approach to the control of asthma symptoms and anxiety. Clinics (Sao Paulo), 67(11), 1291-1297.

Leung, R. S., Floras, J. S., \& Bradley, T. D. (2006). Respiratory modulation of the autonomic nervous system during CheyneStokes respiration. Canadian Journal of Physiology and Pharmacology, 84(1), 61-66. doi:10.1139/y05-145.

Liu, Q.-H., Zheng, Y.-M., Korde, A. S., Yadav, V. R., Rathore, R., Wess, J., \& Wang, Y.-X. (2009). Membrane depolarization causes a direct activation of $\mathrm{G}$ protein-coupled receptors leading to local $\mathrm{Ca} 2+$ release in smooth muscle. Proceedings of the National Academy of Sciences, 106(27), 11418-11423. doi:10. 1073/pnas.0813307106.

Lo, P. C., \& Chang, C. H. (2013). Effects of long-term dharma-chan meditation on cardiorespiratory synchronization and HRV behavior. Rejuvenation Research, 16(2), 115-123.

Malliani, A. (1999). The pattern of sympathovagal balance explored in the frequency domain. Physiology, 14(3), 111-117.

Manzoni, G., Pagnini, F., Castelnuovo, G., \& Molinari, E. (2008). Relaxation training for anxiety: A ten-years systematic review with meta-analysis. BMC Psychiatry, 8(1), 41.

Marshall, R. S., Basilakos, A., Williams, T., \& Love-Myers, K. (2013). Exploring the benefits of unilateral nostril breathing practice post-stroke: Attention, language, spatial abilities, depression, and anxiety. Journal of Alternative and Complementary Medicine,. doi:10.1089/acm.2013.0019.

Masaoka, Y., \& Homma, I. (2000). The source generator of respiratory-related anxiety potential in the human brain. Neuroscience Letters, 283(1), 21-24.

Masaoka, Y., \& Homma, I. (2001). The effect of anticipatory anxiety on breathing and metabolism in humans. Respiration Physiology, 128(2), 171-177. doi:10.1016/S0034-5687(01)00278-X.

McCorry, L. K. (2007). Physiology of the autonomic nervous system. American Journal of Pharmaceutical Education, 71(4), 78.

Meyer, J. S., \& Quenzer, L. F. (2005). Psychopharmacology: Drugs, the brain, and behavior. Sunderland, MA: Sinauer Associates.

Murik, S. E. (2005). Polarization theory of motivations, emotions and attention. Bulletin of Eastern-Siberian Scientific Center SB RAMS, 7, 167-174.

Musazzi, L., Milanese, M., Farisello, P., Zappettini, S., Tardito, D., Barbiero, V. S., et al. (2010). Acute stress increases depolarization-evoked glutamate release in the rat prefrontal/frontal cortex: The dampening action of antidepressants. PLoS One, 5(1), e8566. doi:10.1371/journal.pone.0008566.

Naveen, G. H., Rao, M. G., Vishal, V., Thirthalli, J., Varambally, S., \& Gangadhar, B. N. (2013). Development and feasibility of yoga therapy module for out-patients with depression in India. Indian Journal of Psychiatry, 55(Suppl 3), S350-S356. doi:10.4103/ 0019-5545.116305.
Nemati, A. (2013). The effect of pranayama on test anxiety and test performance. International Journal of Yoga, 6(1), 55-60. doi:10. 4103/0973-6131.105947.

Nesse, R. M., \& Berridge, K. C. (1997). Psychoactive drug use in evolutionary perspective. Science, 278(5335), 63-66. doi:10. 1126/science.278.5335.63.

Newberg, A., Travis, F., Wintering, N., Nidich, S., Alavi, A., \& Schneider, R. (2006). Cerebral 416 glucose metabolic changes associated with Transcendental Meditation practice. Paper presented at the neural imaging, Miami, Fl.

Ospina, M. B., Bond, K., Karkhaneh, M., Tjosvold, L., Vandermeer, B., Liang, Y., et al. (2007). Meditation practices for health: state of the research. Evid Rep Technol Assess (Full Rep)(155), 1-263.

Padival, M., Quinette, D., \& Rosenkranz, J. A. (2013). Effects of repeated stress on excitatory drive of basal amygdala neurons in vivo. Neuropsychopharmacology, 38(9), 1748-1762. doi:10. 1038/npp.2013.74.

Pal, G. K., Velkumary, S., \& Madanmohan, (2004). Effect of shortterm practice of breathing exercises on autonomic functions in normal human volunteers. Indian Journal of Medical Research, 120(2), 115-121.

Patin, A., \& Hurlemann, R. (2011). Modulating amygdala responses to emotion: Evidence from pharmacological fMRI. Neuropsychologia, 49(4), 706-717. doi:10.1016/j.neuropsychologia.2010. 10.004 .

Peupelmann, J., Boettger, M. K., Ruhland, C., Berger, S., Ramachandraiah, C. T., Yeragani, V. K., \& Bär, K.-J. (2009). Cardio-respiratory coupling indicates suppression of vagal activity in acute schizophrenia. Schizophrenia Research, 112(1-3), 153-157. doi:10.1016/j.schres.2009.03.042.

Porta, A., Guzzetti, S., Montano, N., Pagani, M., Somers, V., Malliani, A., et al. (2000). Information domain analysis of cardiovascular variability signals: Evaluation of regularity, synchronisation and co-ordination. Medical and Biological Engineering and Computing, 38(2), 180-188.

Ranabir, S., \& Reetu, K. (2011). Stress and hormones. Indian Journal of Endocrinology and Metabolism, 15(1), 18-22. doi:10.4103/ 2230-8210.77573.

Reznikov, L. R., Grillo, C. A., Piroli, G. G., Pasumarthi, R. K., Reagan, L. P., \& Fadel, J. (2007). Acute stress-mediated increases in extracellular glutamate levels in the rat amygdala: Differential effects of antidepressant treatment. European Journal of Neuroscience, 25(10), 3109-3114. doi:10.1111/j.14609568.2007.05560.x.

Sato, T., Nishishita, K., Kato, Y., Okada, Y., \& Toda, K. (2006). Tonic activity of parasympathetic efferent nerve fibers hyperpolarizes the resting membrane potential of frog taste cells. Chemical Senses, 31(4), 307-313. doi:10.1093/chemse/bjj034.

Schafer, C., Rosenblum, M. G., Kurths, J., \& Abel, H. H. (1998). Heartbeat synchronized with ventilation. Nature, 392(6673), 239-240. doi:10.1038/32567.

Seals, D. R., Suwarno, N. O., \& Dempsey, J. A. (1990). Influence of lung volume on sympathetic nerve discharge in normal humans. Circulation Research, 67(1), 130-141. doi:10.1161/01.res.67.1. 130.

Sequeira, H., Hot, P., Silvert, L., \& Delplanque, S. (2009). Electrical autonomic correlates of emotion. International Journal of Psychophysiology, 71(1), 50-56. doi:10.1016/j.ijpsycho.2008. 07.009 .

Song, H. S., \& Lehrer, P. M. (2003). The effects of specific respiratory rates on heart rate and heart rate variability. Applied Psychophysiology and Biofeedback, 28(1), 13-23.

St Croix, C. M., Satoh, M., Morgan, B. J., Skatrud, J. B., \& Dempsey, J. A. (1999). Role of respiratory motor output in within-breath modulation of muscle sympathetic nerve activity in humans. Circulation Research, 85(5), 457-469. 
Starcevic, V. (2012). Benzodiazepines for anxiety disorders: Maximising the benefits and minimising the risks. Advances in Psychiatric Treatment, 18(4), 250-258. doi:10.1192/apt.bp.110. 008631.

Storm, H., Myre, K., Rostrup, M., Stokland, O., Lien, M. D., \& Raeder, J. C. (2002). Skin conductance correlates with perioperative stress. Acta Anaesthesiologica Scandinavica, 46(7), 887-895.

Streeter, C. C., Gerbarg, P. L., Saper, R. B., Ciraulo, D. A., \& Brown, R. P. (2012). Effects of yoga on the autonomic nervous system, gamma-aminobutyric-acid, and allostasis in epilepsy, depression, and post-traumatic stress disorder. Medical Hypotheses, 78(5), 571-579. doi:10.1016/j.mehy.2012.01.021.

Streeter, C. C., Jensen, J. E., Perlmutter, R. M., Cabral, H. J., Tian, H., Terhune, D. B., et al. (2007). Yoga Asana sessions increase brain GABA levels: A pilot study. Journal of Alternative and Complementary Medicine, 13(4), 419-426. doi:10.1089/acm. 2007.6338.

Stubenrauch, J. M. (2011). Meditation as good as medication? AJN The American Journal of Nursing, 111(3), 16. doi:10.1097/1010. 1097/1001.NAJ.0000395224.0000379799.0000395232.

Sztajzel, J. (2004). Heart rate variability: A noninvasive electrocardiographic method to measure the autonomic nervous system. Swiss Medical Weekly, 134(35-36), 514-522.

Taylor, V. A., Grant, J., Daneault, V., Scavone, G., Breton, E., RoffeVidal, S., et al. (2011). Impact of mindfulness on the neural responses to emotional pictures in experienced and beginner meditators. Neuroimage, 57(4), 1524-1533. doi:10.1016/j.neuro image.2011.06.001.

Telles, S., Nagarathna, R., \& Nagendra, H. R. (1995). Autonomic changes during "OM" meditation. Indian Journal of Physiology and Pharmacology, 39(4), 418-420.

Topchiy, I., Radulovacki, M., Waxman, J., \& Carley, D. W. (2011). Impact of the vagal feedback on cardiorespiratory coupling in anesthetized rats. Respiratory Physiology and Neurobiology, 175(3), 375-382. doi:10.1016/j.resp.2010.12.017.

Vandana, B., Vaidyanathan, K., Saraswathy, L. A., Sundaram, K. R., \& Kumar, H. (2011). Impact of integrated amrita meditation technique on adrenaline and cortisol levels in healthy volunteers. Evidence Based Complement Alternative Medicine, 2011, 379645. doi:10.1155/2011/379645.

Vrijkotte, T. G. M., van Doornen, L. J. P., \& de Geus, E. J. C. (2000). Effects of work stress on ambulatory blood pressure, heart rate, and heart rate variability. Hypertension, 35(4), 880-886. doi:10. 1161/01.hyp.35.4.880.

Wahlestedt, C., Pich, E., Koob, G., Yee, F., \& Heilig, M. (1993). Modulation of anxiety and neuropeptide Y-Y1 receptors by antisense oligodeoxynucleotides. Science, 259(5094), 528-531. doi:10.1126/science.8380941.

Wallace, R. K. (1970). Physiological effects of transcendental meditation. Science, 167(3926), 1751-1754.

Wallace, R. K., Benson, H., \& Wilson, A. F. (1971). A wakeful hypometabolic physiologic state. American Journal of Physiology, 221(3), 795-799.

Wijsman, J., Grundlehner, B., Penders, J., \& Hermens, H. (2010). Trapezius muscle EMG as predictor of mental stress. Paper presented at the Wireless Health 2010, San Diego, California.

Wood, C. (1993). Mood change and perceptions of vitality: A comparison of the effects of relaxation, visualization and yoga. Journal of the Royal Society of Medicine, 86(5), 254-258.

Wu, L. J., Gao, Z., Chen, B., Koval, O. M., Singh, M. V., Guan, X., et al. (2009). Calmodulin kinase II is required for fight or flight sinoatrial node physiology. Proceedings of the National Academy of Sciences United States of America, 106(14), 5972-5977. doi:10.1073/pnas.0806422106.

Wu, L. J., Ko, S. W., Toyoda, H., Zhao, M. G., Xu, H., Vadakkan, K. I., et al. (2007). Increased anxiety-like behavior and enhanced synaptic efficacy in the amygdala of GluR5 knockout mice. PLoS One, 2(1), e167. doi:10.1371/journal.pone.0000167.

Wu, S. D., \& Lo, P. C. (2010). Cardiorespiratory phase synchronization during normal rest and inward-attention meditation. International Journal of Cardiology, 141(3), 325-328. doi:10.1016/j. ijcard.2008.11.137.

Youngstedt, S. D., \& Kripke, D. F. (2007). Does bright light have an anxiolytic effect?-An open trial. BMC Psychiatry, 7, 62. doi:10.1186/1471-244x-7-62.

Zagon, A., \& Kemeny, A. A. (2000). Slow hyperpolarization in cortical neurons: A possible mechanism behind vagus nerve simulation therapy for refractory epilepsy? Epilepsia, 41(11), $1382-1389$.

Zhang, J., Yu, X., \& Xie, D. (2010). Effects of mental tasks on the cardiorespiratory synchronization. Respiratory Physiology and Neurobiology, 170(1), 91-95. doi:10.1016/j.resp.2009.11.003.

Zope, S. A., \& Zope, R. A. (2013). Sudarshan kriya yoga: Breathing for health. International Journal of Yoga, 6(1), 4-10. doi:10. 4103/0973-6131.105935. 